\title{
Relatos de Experiência: a Construção de Professores na Educação de Jovens e Adultos
}

\author{
Experience Reports: A Teacher Building in Youth and Adult Education \\ Relatos de Experiencia: La Construcción de Profesores en la Educación \\ de Jóvenes y Adultos
}

\author{
Everson dos Santos Gonçalves ${ }^{1}$ \\ Everton Ferrer de Oliveira ${ }^{2}$
}

\begin{abstract}
Resumo
O presente trabalho de pesquisa foi desenvolvido com base no projeto de extensão "Manutenção e desenvolvimento de comunidade de aprendizagem virtual multimídia em rede social na Educação de Jovens e Adultos - Portal dos Fóruns de Educação de Jovens e Adultos (EJA do Brasil)" na Universidade Federal do Pampa (UNIPAMPA) Campus Jaguarão/RS, que mantém três frentes de ações: A alfabetização popular, a formação inicial e continuada de educadores para EJA assim como a manutenção do site fórum EJA-RS. O objetivo geral da pesquisa foi realizar um mapeamento dos conflitos socioambientais na comunidade próxima à universidade federal do pampa onde residem os educandos. Nossa abordagem teórica é a freireana para o estabelecimento do contexto didático educacional e do universo vocabular na aprendizagem dos educandos sintonizados aos temas da realidade deles. Dentro deste contexto, foram elaboradas algumas atividades reflexivas com os alfabetizandos, com o intuito de problematizar os conflitos ambientais do seu bairro, por meio de apresentação de fotos e imagens provocativas, através das quais foram evidenciadas a relação com o Patrimônio Ambiental, Cultural e Arquitetônico. As práticas alfabetizadoras são desenvolvidas duas vezes na semana por acadêmicos de múltiplos cursos superiores, ligados a diferentes programas da universidade federal do pampa.
\end{abstract}

Palavras-Chave: Educação Ambiental; Educação De Jovens E Adultos; Meio Ambiente; Outro; Patrimônio.

\section{Resumen}

El presente trabajo de investigación fue desarrollado con base en el proyecto de extensión "Mantenimiento y desarrollo de comunidad de aprendizaje virtual multimedia en red social en la Educación de Jóvenes y Adultos Portal de los Foros de Educación de Jóvenes y Adultos (EJA de Brasil)" en la UNIPAMPA campus Jaguarão/RS que mantiene três frentes de acciones:La alfabetización, la formación inicial y continuada de educares para EJA así como el mantenimiento del sitio foro EJA-RS. El objetivo general de la investigación fue realizar un mapeamiento de los conflictos socioambientales en la comunidad cercana a la universidad federal del pampa donde residen los educandos. Nuestro enfoque teórico es la freireana para el establecimiento del contexto didáctico educativo y del universo vocabular en el aprendizaje de los educandos sintonizados a los temas de su realidad. En este contexto, se elaboraron algunas actividades reflexivas con los alfabetizandos, con el propósito de problematizar los conflictos ambientales de su barrio, por medio de presentación de fotos e imágenes provocativas, a través de las cuales se evidenció la relación con el Patrimonio Ambiental, Cultural y Arquitectónico. Las prácticas alfabetizadoras se desarrollan dos veces en la semana por académicos de múltiples cursos superiores, ligados a diferentes programas de la universidad federal de la pampa.

${ }^{1}$ (Graduando no Curso Superior em Tecnologia de Gestão em Turismo pela Universidade Federal do Pampa (UNIPAMPA) - Campus Jaguarão/RS/Brasil - Atualmente é bolsista do Núcleo de Inclusão e Acessibilidade da Unipampa. E-mail: Everson.turismo@gmail.com).

${ }^{2}$ (Professor Adjunto pela Universidade Federal do Pampa - Campus Jaguarão/RS/Brasil, Doutorando do Programa de Pós-Graduação em Educação Ambiental/PPGEA/FURG. E-mail: evertonoliveira@unipampa.edu.br). 
Palabras claves: Educación ambiental; Educación de Jóvenes y Adultos; Medio ambiente; Otro; Patrimonio.

\begin{abstract}
This research was developed based on the project "Maintenance and development of multimedia virtual learning community in social network in Youth and Adult Education - Portal of Formulas for Youth and Adult Education (EJA Brazil)" at the University Federal University of Pampa (UNIPAMPA) Campus Jaguarão / RS, which maintains three fronts of actions: A popular literacy, an initial and ongoing training of educators for EJA, as a maintenance of the EJA-RS forum site. The general objective of the research is to carry out a mapping of social and environmental conflicts in the community near the federal university of the pampas where the students live. Our theoretical approach is a Freirean for the establishment of the educational didactic context and the vocabulary universe in the learning of the students attuned to the themes of their reality. Within this context, some reflective activities were carried out with the literacy students, in order to prove the environmental conflicts of their neighborhood, through the presentation of provocative photos and images, through which the relation with Environmental, Cultural and Architectural Heritage was evidenced. Literacy practices are developed twice a week by academics of multiple higher education courses, linked to different programs at the Federal University of Pampas.
\end{abstract}

Keywords: Environmental education; Youth and Adult Education; Environment; Other; Patrimony.

\title{
1. Introdução
}

O presente trabalho faz referência a ações de alfabetização e de educação ambiental com uma turma de Educação de Jovens e Adultos (EJA) comporta por cinco alunos de idade média de 50 anos, é um projeto de extensão centrado na Universidade Federal do Pampa, onde tive a oportunidade de atuar ministrando aulas, oficinas e a manutenção de um site, no ano de 2016. O projeto foi elaborado por um professor do curso superior de licenciatura em pedagogia da universidade federal do pampa. Ao longo do processo do projeto, o objetivo era de pesquisar e realizar um mapeamento dos conflitos socioambientais da comunidade próxima à universidade federal do pampa onde residem os educandos.

Para o estudo foram realizadas duas pesquisas de campo, a aplicação de um questionário de perfil socioeconômico e um mapeamento dos conflitos socioambientais por meio de idas e observações na comunidade próxima à Universidade Federal onde residem os educandos. Estas atividades foram desenvolvidas com o apoio do Programa de Desenvolvimento Acadêmico (PDA) e pelo Programa Institucional de Bolsa de Iniciação à Docência (PIBID), do curso superior em Licenciatura de Pedagogia da Universidade Federal do Pampa (UNIPAMPA) campus Jaguarão no estado do rio grande do sul, Brasil. É uma pesquisa de caráter exploratório, visto que existem poucos estudos ainda feitos.

\section{Metodologia}

A pesquisa pode ser caracterizada como um estudo exploratório, pois busca constatar mais informações sobre o tema. De acordo com Gerhardt e Silveira (2009): 
Este tipo de pesquisa tem como objetivo proporcionar maior familiaridade com o problema, com vistas a torná-lo mais explícito ou a construir hipóteses. A grande maioria dessas pesquisas envolve: (a) levantamento bibliográfico; (b) entrevistas com pessoas que tiveram experiências práticas com o problema pesquisado. (c) análise de exemplos que estimulem a compreensão. (GERHARDT e SILVEIRA, 2009 , p. 35)

A instrumentalização utilizada para a respectiva pesquisa foi realizada através de uma revisão bibliográfica, tendo como base a exploração de artigos acadêmicos publicados em revistas, anais de eventos e sítios da Internet, bem como entrevistas de moradores do bairro. Para o trabalho foram realizadas pesquisas bibliográficas abordando o tema Educação de Jovens e Adultos, com ênfase na Educação Ambiental, utilizando autores como Freire (1987), Maturana (2002), Pereira 2016, Ocanã 2006. Na saída de campo foi realizada a aplicação de um questionário socioeconômico e entrevistas com moradores do bairro, onde residem os alunos do projeto, para reunir informações sobre os conflitos socioambientais.

3. O processo de educação ambiental na educação de jovens e adultos

Mesmo com toda a tecnologia contemporânea e o conhecimento cientifico, o ser humano moderno ainda não aprendeu o verdadeiro valor do meio ambiente. Vimos no ano de 2015, um grande acidente da mineração brasileira no município de Mariana, em Minas Gerais. O rompimento de uma barragem provocou uma enxurrada de lama que devastou o distrito de Bento Rodrigues, deixando um rastro de destruição à medida que avançava pelo Rio Doce. A tragédia causou diversas mortes e várias pessoas ficaram desabrigadas, com pouca água disponível. No ano seguinte, 2016, acontece outro acidente onde caí uma parte da ponte Tim Maia, na Avenida Niemeyer, em São Conrado, na Zona Sul do Rio de Janeiro, com de cerca de 20 metros, devido a uma onda forte que ocasionou o desastre, gerando mais mortes e dramas no país. Deste modo, compreendesse a importância da educação ambiental na educação de jovens e adultos, pois não basta apenas conservar e preservar, mas sim educar, porque só desta maneira a sociedade civil poderá ser capaz de compreender o verdadeiro valor da natureza e assim formar consciência da necessidade de se educar ambientalmente.

Em um primeiro momento, antes de começar as atividades com a turma de EJA, tive reuniões com a representante do Fórum EJA de Brasília, diretamente da Universidade de Brasília (UNB) por meio de vídeo-chamadas no software denominado Skype, onde ela me passava todas as orientações para a manutenção da página do Fórum EJA. Pois, além de ministrar oficinas e aulas meu trabalho também era de atualizar o site do fórum EJA do estado do Rio Grande do Sul com materiais didáticos e novidades do cenário educacional. 
Ao planejar as atividades de sala de aula, criei um grupo de estudo com discentes interessados em ajudar no projeto, onde seus objetivos eram de auxiliar e discutir sobre as atividades a serem desenvolvidas do projeto. Na sala de aula com os educandos, pensamos em criar atividades que pudessem ser construtivas e reflexivas para que os alunos se constituíssem cidadãos mais críticos com os problemas socioambientais do cotidiano. Logo, queríamos conhecer mais sobre os alunos, no primeiro encontro com os educandos foram aplicados questionários simples perguntando dados básicos dos alunos com o intuito de obter um pouco mais de informação sobre eles.

Em seguida, ao analisar os questionários foi descoberto que vários dos alunos moram no mesmo bairro que fica próximo à Universidade Federal do Pampa, denominado Cerro da Pólvora. Prontamente, começamos a pensar em uma atividade que os reunissem como moradores desse bairro. Fiquei curioso com os dados coletados, ao passar da semana fui visitar o bairro, pois queria muito saber mais sobre os educandos. Freire já nos trazia a questão da necessidade de entender o contexto dos educandos para construir um ambiente harmônico em aula de sala.

Chegando no bairro, tive a oportunidade de tirar algumas fotos belíssimas do bairro, pois a vista do lugar e o pôr do sol que se encontram são elementos paradisíacos e peculiares do lugar, porém o espaço geográfico-físico não estava em boas condições, encontrava-se precário e muito sujo pela poluição socioambiental. Observando no bairro, avistasse uma antiga pedreira de granito com um formato muito peculiar, no espaço da comunidade habitam diversos animas da fauna que formam o belo bioma pampa, no entanto se vê um descuidado com o ambiente dessas belezas naturais. Refletindo sobre os fatos da comunidade, em seguida pensei em levar aquelas imagens que tirei para dentro da sala de aula e problematizar junto aos alunos do projeto.

\section{Sensibilizar e conscientizar para educar}

No dia seguinte, levei as fotos do bairro para dentro da sala de aula e reproduzi no aparelho de data show e pedi, por gentileza, que os alunos observassem e me falassem palavras que remetesse lembranças a eles, desta maneira trabalhando suas memorias e suas escritas. Em seguida, os educandos observando as fotos me responderam as seguintes palavras: Saneamento básico, educação e palavras simultâneas. Observe a figura abaixo: 


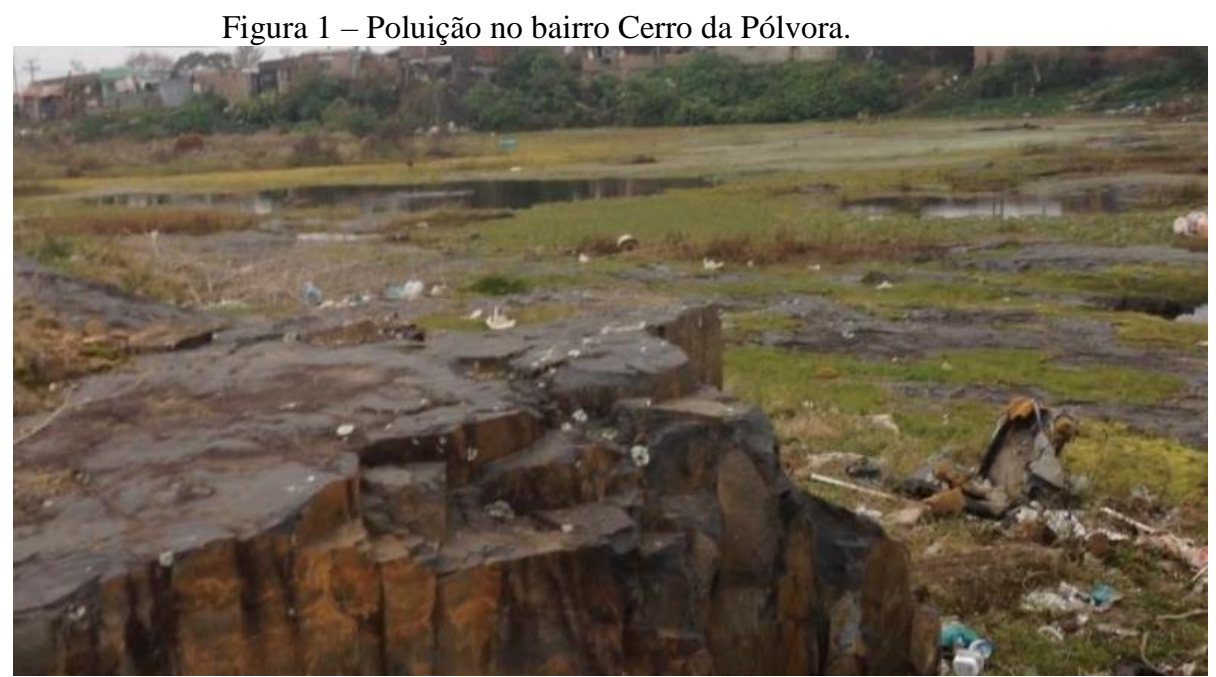

Fonte: Própria do autor, 2016.

Com o assunto ambiental em pauta, os educandos comentaram que fazem parte de uma associação de morados do bairro e que estavam tentando lutar para que a prefeitura municipal desenvolvesse ações de limpeza do bairro, em prol de uma melhor qualidade de vida para os moradores. E encima disso fomos trilhando nosso caminho com a Educação Ambiental e com a alfabetização dos educandos do projeto.

Ao final da aula pedi que levassem objetos ou notícias de temáticas do seu cotidiano para sala de aula. Continuamente trabalhando questões contemporâneas, problematizando elementos do convívio e do cotidiano deles. Pois, não basta só sensibilizar e conscientizar, é necessário educar. Para que desta maneira formem-se sujeitos críticos, e assim tomem consciência da necessidade de se Educar Ambientalmente e garantir o futuro das próximas gerações.

É indispensável à construção de uma consciência ambiental diária seja ela em: Sala de aula, em movimentos sociais, em organizações não governamentais (ONG), em ações coletivas que pensem no todo em prol de uma ecologia sustentável e de um mundo mais equilibrado. E quando se aborda a sustentabilidade, se fala nas questões de emancipação social, econômica, ambiental e cultural. Para a construção de uma sociedade civil mais justa e participativa, não apenas voltada para as ações do ser humano como centro do universo. Observasse à luta diária, por meio das redes sociais, das organizações não governamentais em destaque as ações do Green Peace que não se cansam da militância em prol do meio ambiente, no entanto ainda assim se vê que a voz perante o cenário político brasileiro ainda é ineficiente. Em 2015, Bill Gates fundador da Microsotf e um dos homens mais ricos do mundo, investe em um projeto na África Ocidental capaz de transformar fezes em água limpa ou energia 
elétrica. Percebesse que processos ecológicos que para muitos não passava de mais uma utopia recentemente tem mudado a vida de várias pessoas pelo globo.

\section{O valor imaterial dos patrimônios}

Na comunidade dos educandos se deparamos também com uma obra em andamento na antiga enfermaria militar, local de importância histórica e cultural para o município e para o bairro. O projeto para a antiga enfermaria, é que seja restaurada e que vire um museu contando a história da cidade e resgatando sua identidade local, a Universidade Federal do Pampa juntamente com a Prefeitura Municipal, se vinculou ao projeto que é denominado Centro de Interpretação do Pampa. O Instituto Patrimônio Histórico e Artístico Nacional (IPHAN) apoiou o projeto de restauração da enfermaria que futuramente irá trazer turistas e consequentemente mais renda e infraestrutura para o bairro, mas para isso precisasse trabalhar a educação ambiental na região.

Todavia na mesma localidade subjazem grandes galerias de granito, que tem uma grande importância imaterial para os moradores o bairro. Pois, foi onde muitos dos moradores tiravam sua renda em tempos de crise. Estas galerias de granito que formam um bioma peculiar e apesar de sua beleza expendida são aproveitadas como repositor de lixo da comunidade, pela ausência de saneamento básico e ações ambientais afirmativas por parte da prefeitura municipal (meio urbano e meio rural). De acordo com Saito (2002):

A Política Nacional de Educação Ambiental para a construção de uma cidadania ativa e crítica que, além de desvelar as relações de dominação (opressão social) em nossa sociedade, indica a necessidade de remeter-se à prática de uma ação transformadora intencional (SAITO, 2002, p. 45)

Como o autor bem aborda, é preciso conscientizar os morados do bairro da importância da educação ambiental e das belezas naturais que ali se encontram, no entanto cabe ressaltar que o poder público municipal e a secretário de meio ambiente devem dar mais importância para a questão ambiental da comunidade como também criar politicas públicas mais rígidas com o intuito de um maior incentivo da preservação do patrimônio natural que naquele bairro se encontra.

De acordo com entrevista feita com moradores do bairro, os relatos são de que muitos cidadãos do bairro foram vitimas do desemprego no município e tiveram que optar por trabalhar com o elemento natural que em seu bairro se encontra: As canteiras, rochas que eram sido quebradas com martelo por uma mão de obra não qualificada e mal remunerada, 
formando britas para serem vendidas no mercado da construção civil. Com pouca renda e difícil acesso, muitos destes morados não tiveram a oportunidade de estudar, foram criando suas famílias com pouco dinheiro e eram obrigados a trabalhar para terem acesso ao suprimento de suas necessidades básicas.

Com o passar dos anos, as novas tecnologias foram se instalando no mercado consumidor. Com isso, gerando demanda por novas formas de pagamento, a comunidade carente em empreendedorismo ia sendo excluída do mercado por empreendedores com maior valor aquisitivo financeiro, oferecendo parcelamentos mensais e compras com cartões de créditos, facilitando as demandas do mercado consumidor, fazendo com que muitos dos graniteiros fossem perdendo seu espaço no mercado e a renda de sua comunidade, tendo que ir procurar trabalho em outros lugares e cidades.

Uma das perguntas mais importante do questionário socioeconômico foi se as pedreiras tem valor para a comunidade, a pesquisa foi realizada com 9 famílias que residem no bairro Cerro da Pólvora, dividida em dois de pesquisa. Observe logo a seguir o quadro da pesquisa:

Gráfico 1. Considera as canteiras importantes para o bairro?

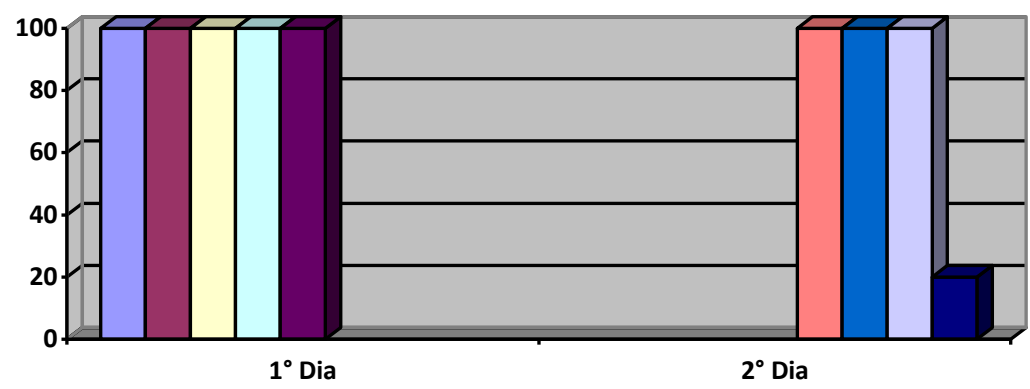

Fonte: Próprio autor, 2017.

Observando o gráfico, percebesse que no segundo dia de pesquisa apenas uma das nove famílias não consideram as pedreiras um bem tão importante para o bairro. Afirmando que não consideram sua importância devido às pedreiras se encontrarem em um estado precário de limpeza, se estivessem mais adequadas teriam mais valor diz o morador. Já as oito famílias restantes reconhecem a história da pedreira e dizem que por muitos anos esse bem era considerado fonte de renda para a comunidade, valorizando sua importância.

A pesquisa também pode coletar dados quanto ao nível de renda familiar do bairro. Veja a seguir a ilustração: 
Gráfico 2. Renda familiar.
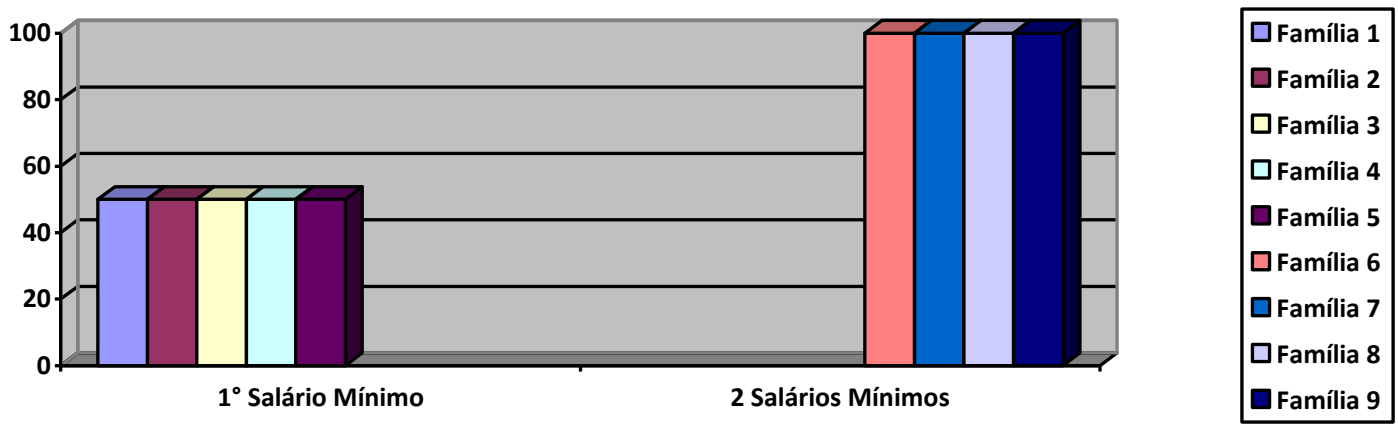

Fonte: Próprio Autor, 2017.

Observou-se que a renda familiar da comunidade é de aproximadamente um salário mínimo tendo variantes até dois salários.

\section{Patrimônio, meio ambiente e conflitos}

Em aula, trabalhando com a Pauta da Educação Ambiental, os educando nos relatam dos conflitos entre os morados do bairro com o poder público. A associação dos moradores do bairro além de conscientizar os vizinhos de que não devem colocam lixo nos espaços públicos, ainda tem uma luta diária com o poder público para que sejam feita ações de conscientização ambiental e limpeza no bairro.

Um dos viés da Educação de Jovens e Adultos é formar cidadãos mais críticos, menos robóticos e conscientes. Segundo Freire (1987, p. 44), não é no silêncio que os homens se fazem, mas na palavra, no trabalho, na ação reflexiva. Logo, fomos levando temas relevantes para os educandos e aos pouco íamos tendo resultados positivos. Com o passar do tempo, os alunos iam se politizando como cidadãos providos de direitos civis e levando suas demanda para a associação do bairro e cobrando por melhorias do poder público. Segundo Ocanã e Jimenez (2016):

Sabemos que não existem alunos irrecuperáveis e que qualquer adolescente que frequente nossa escola, por atrasado que esteja em relação à sua idade, pode progredir se for atendido individualmente e partindo sempre de seus conhecimento iniciais e necessidades imediatas.(OCANÃ e JIMÉNEZ, 2016, p. 25)

Assim como Ocanã e Jiménez, acreditamos que não exista tempo perdido, é preciso ser humilde e aprender a recomeçar, às vezes é necessário passar por situações de conflito 
para saber o valor das coisas. Afinal quem disse que tem idade certa para algumas coisas, cada um eventualmente terá o seu tempo para tudo.

Para Bolzan (2002) “a base de toda a atividade cooperativa é a ação conjunta, há negociação de conflitos, estabelecendo-se uma teia de relações que compõem o processo interativo de funcionamento assimétrico“. Bolzan, nos trás que o papel do professor, não é só passar o conteúdo, mas como também despertar provocações, reflexões, debates para que os educandos cresçam didaticamente, assim como o professor tem muito que aprender com os alunos, ambos vão se construindo e se descontruindo cotidianamente em aula.

\subsection{Pedreira e enfermaria militar}

No bairro dos educandos, se encontra um bem ambiental de grande importância para os moradores, à pedreira também chamada de canteira, onde são contadas muitas histórias por cidadãos do bairro. De acordo com relatos de morados do bairro, foi com as pedras da pedreira que surgiu a própria Enfermaria Militar e a formação de muitas das casas do município de Jaguarão e região.

É do granito extraído desse bem natural que foram construídas diversas obras do município. No entanto, a mesma pedreira não tem um reconhecimento municipal pela prefeitura local, muito menos pelo Instituto do Patrimônio Histórico e Artístico Nacional (IPHAN) ou pela Organização das Nações Unidas para a Educação, a Ciência e a Cultura (UNESCO). De acordo com Villas Boas (2012):

\footnotetext{
A Enfermaria Militar de Jaguarão é um prédio em estilo neoclássico localizado no bairro Cerro da Pólvora, no município de Jaguarão/RS, construído no século XIX cerca de 1880 e 1883, com a finalidade de atender os militares do exército da região e da campanha e que atualmente servirá de base para a implantação do Centro de Interpretação do Pampa (CIP), complexo cultural que contará com museu, anfiteatro e auditório subterrâneo, além de prédio de apoio para desenvolvimento de atividades de ensino, pesquisa e extensão. (VILLAS BOAS, 2012, p. 1)
}

Segundo Villas Boas (2012), o prédio foi construído ao redor de um pátio interno, com amplas janelas e porão alto, uma sólida construção de alvenaria conjugada com pedras oriundas de uma pedreira próxima. $\mathrm{O}$ autor descreve muito bem a matéria prima que foi utilizada para a construção da Enfermaria Militar, entretanto as pedreiras em volta da comunidade encontram-se muito poluídas por lixos da comunidade civil que sofrem com a precariedade de ações de desenvolvimento de saneamento básico e de ações de fomento a importância da educação ambiental para o bairro. 
As canteiras por muito tempo foram à forma de renda da comunidade civil, onde muitos moradores extraiam produtos minerais não metálicos ou carboníferos e, em particular, pedras destinadas a obras de arte e construções de casas como o mármore e o granito. Segundo Jorge (2007):

Patrimônio sempre teve a ver com identidade, com valores não materiais, simbólicos, e com a memória dos indivíduos e dos grupos. Sem memória não há pessoa, não há projecto, não há sentido de comunidade - só máquinas deliberantes e egoístas, mostros em que tememos transforma-nos (JORGE, 2007, p.20).

Como Jorge bem ressalta, o povo de uma comunidade tem o direito e o dever de se identificar e se sentir representado por seu patrimônio seja ele material ou não, de entender sua própria história e sua cultura. São nas articulações dos grupos sociais, nas associações, nas representações políticas que começam os embasamentos e os pertencimentos, formando um coletivo de unidade representativa de luta para o bairro. Uma vez que o povo não conhece sua história acaba sendo robotizado, automático e manipulado facilmente. É necessário seguir trabalhando em ações por uma melhor qualidade de vida para a comunidade e para o município.

\section{O sistema que estamos inseridos}

A globalização nos mostra que os país mais desenvolvidos são os mais capitalistas, logo a mídia nos faz acreditar que devemos seguir esse padrão Eurocentrico de que tudo que vem da Europa é excelente. Em seguida, aos poucos vamos sendo manipulados pelo sistema, pelos desenhos animados, pelos cinemas, pelas comidas, pelas roupas, enfim pelos mais diversos elemento do mercado consumidor.

O sistema capitalista esta inserido bem ao nosso lado, muito vezes sem nem percebermos. Frequentemente compramos objetos que nem se quer fazemos uso, como por exemplo, quem não tem aquela velha roupa no armário que não usa mais há muito tempo. Eventualmente muitos cidadãos jogam seus pertences inúteis fora e assim se acumula mais lixo no planeta, ao invés de fazer doações para aqueles que realmente precisam.

A necessidade de consumirmos objetos fúteis esta enraizado na nossa cultura brasileira, e este fato precisa ser desconstruído aos poucos. O sentido de nunca estar completo, preenchido por uma falsa sensação de felicidade que dura pouco tempo, confortável ilusão parece liberdade, mas na verdade é uma prisão. É uma necessidade de procurar estar na 
moda, de ter aceitação por grupos sociais, por status social nas diversas camadas da sociedade civil, são os fatos que se compreende na contemporaneidade.

Atualmente as pessoas não se falam, mas sim se calam. Em pleno século XXI as conversas são tão artificiais, quanto ter amigos imaginários, os seres humanos conversam usando o wifi dos estabelecimentos de lazer e não interagem entre si como deveriam a interação social parece estar ligada no automático. Após a revolução tecnológica a vida tem se tornado automática, robótica e alienada. Não entendo que a tecnologia seja um retrocesso, porém é necessário usarmos ela e não ela nos usar, não sejamos escravos da tecnologia que nos cerca. Poucas pessoas saem do trabalho e param 10 minutos do seu dia para contemplar o pôr do sol. São raros os país que conseguem passam mais tempo do seu dia com seus filhos(a) do que trabalhando. Como descreve Maturana (2002, p. 24) é necessário entender o outro como legítimo outro na convivência. Este outro pode ser a sua família, o seu vizinho, o seu animal de estimação ou o meio ambiente como um todo. De acordo com Robers, Oliveira e da Silva (2014):

\begin{abstract}
De modo semelhante, o projeto de uma vida mais bonita empreendido por Maturana tem a ver com o cuidar do outro. $\mathrm{O}$ outro pode ser, por exemplo, o meio ambiente. Nesse exemplo, cuidar do meio ambiente significa cuidar de si e do outro - se aqui este "outro" como o vizinho ou o oriental que reside do outro lado do globo; os animais não-humanos, os insetos e as plantas; as águas, o ar, a terra e o planeta Terra. (ROBERS; OLIVEIRA; da Silva, 2014, p.5)
\end{abstract}

Assim como somos seres bio-psico-socio-amb-espirituais. Não somos só partes distintas, somos um complexo todo. Logo precisamos interagir com o outro na convivência, como legitimo outro formando uma sintonia com o meio ambiente que esta a nossa volta. Os grandes centros urbanos do Brasil nos mostram o quanto viramos seres humanos competitivos cotidianamente, observasse o estresse que é morar nos grandes centros urbanos na atualidade: Com o trânsito em horário de pico, as brigas diárias, as guerras, o estresse excessivo e a poluição sonora. É necessário tirar férias desse estresse das capitais do país. E como é complexo pensar que a gente vê tanta tecnologia nos grandes centros e nenhuma capaz de acabar com a corrupção, a miséria e a fome do mundo. Portanto, neste sentido, constituímonos sujeitos-atores de uma sociedade mais igualitária, buscando a perspectiva de melhor qualidade de vidas para todos. 


\section{Conclusões}

A pesquisa permitiu fazer uma investigação e obter informações significativas para compreensões da situação dos conflitos ambientais do bairro dos educandos, do cotidiano dos alunos, assim como dos seus conhecimentos básicos. Levando em conta essa informação, podemos afirmar que a educação ambiental vem mudando vidas e formando cidadãos mais críticos e conscientes.

É sempre uma tarefa árdua trabalhar com turmas de EJA no Brasil, pois é um público com uma vasta diversidade cultural. É necessário ir desbravando aos poucos, com paciência, suas peculiaridades. A convivência social se estabelece e se constitui na aceitação do outro, no respeito e na confiança recíproca, criando assim um espaço comum de convívio. E nessa aceitação, nesse respeito e nessa confiança mútuos é que se constitui a liberdade social gerando laços de amizades com o outro, como legitimo outro na convivência.

Ficou evidente também, que os alunos têm o desejo de sabem mais da importância de seus patrimônios e de sua história, de seus direitos civis e assim como suas inquietações de lutar e cobrar por uma melhor qualidade de vida para sua comunidade, como um grupo engajado, para que às pessoas responsáveis cumpram com o que é deles por direito.

Quanto ao tema da educação ambiental, é possível afirmar que após a realização deste estudo, percebeu-se a falta de compreensão ou de informação que possibilita uma percepção falsa ou distorcida do que é a EA, visto somente a achar que é só cuidar dos biomas, da fauna, da flora ou o que muitos descrevem ser uma eventualidade utópica. No entanto, se vê que a Educação Ambiental é entender o outro, as relações humanas, a diversidade cultural, o meio ambiente, a biodiversidade e é entender os meios de produção. Assim como Bill Gates nos mostra, em 2015, que a ecologia pode ser amiga da nova tecnologia.

Portanto, é necessária uma conscientização diária da educação ambiental seja ela em: Sala de aula, em movimentos sociais, em ONG,s, em ações coletivas que pensem em prol de um mundo melhor e com uma qualidade de vida melhor para todas e todos. Torna-se indispensável, trabalhar ações de fomento da educação ambiental, pois uma comunidade muito carente que vive com pouco acesso as coisas básicas sempre precisará de cidadãos críticos. Poucos moradores do bairro tem acesso ainda ao ensino superior, a uma vida autônoma, é imprescindível mudanças de mentalidades. Segundo Paulo Freire, não existe imparcialidade. Afinal qual é o legado que queremos deixa para as gerações futuras a educação inclusiva ou excludente? A nossa é a inclusiva. 


\section{Referências}

Bolzan, D. Formação de Professores: Compartilhando e Reconstruindo conhecimentos/Dóris Pires Vargas Bolzan. - Porto Alegre: Editora Mediação, 2002.

Freire, P. Pedagogia do oprimido. 16a ed. Rio de Janeiro: Paz e Terra, 1987. Disponível em: <http://www.dhnet.org.br/direitos/militantes/paulofreire/paulo_freire_pedagogia_do_oprimid o.pdf > Acesso em: 13 nov. 2016.

GERHARDT, T.; SILVEIRA, D. Métodos de pesquisa / [organizado por] Tatiana Engel Gerhardt e D. T. Silveira ; coordenado pela Universidade Aberta do Brasil - UAB/UFRGS e pelo Curso de Graduação Tecnológica - Planejamento e Gestão para o Desenvolvimento Rural da SEAD/UFRGS. - Porto Alegre: Editora da UFRGS, 2009. Disponível em < http://www.ufrgs.br/cursopgdr/downloadsSerie/derad005.pdf> Acesso em: 1 nov. 2016.

JORGE, V. OLIVEIRA. Arqueologia, Património e Cultura. Lisboa, Editora Instituto Piaget, 2007. (2 Edição)

LÓPEZ OCANÃ, ANTONIO M.a A atenção à diversidade na educação de jovens/ Antonio M.a López Ocanã e Manuel Zafra Jiménez; Ernani Rosa. - Porto Alegre : Artmed, 2006.

MATURANA, R., HUMBERTO. Emoções e linguagem na educação e na política / Humberto Maturana; tradução: José Fernando Campos Fortes. - Belo Horizonte: Ed. UFMG, 2002.Disponível em: http://fvcb.com.br/site/wpcontent/uploads/2016/07/Emo\%C3\%A7\%C3\%B5es-e-Linguagem-naEduca\%C3\%A7\%C3\%A3o-e-na-Pol\%C3\%ADtica.pdf> Acesso em: 26 nov. 2016.

ROBERS, DANUSA S., GABRIELA F. OLIVEIRA e GIOVANA B. da SILVA. Por uma vida bonita: o reconhecimento do outro como legítimo outro, a liderança ética e servidora e o cuidado de si - reflexões acerca da educação e da gestão de pessoas mediadas por maturana e Foucault. XIV COLÓQUIO INTERNACIONAL DE GESTÃO UNIVERSITÁRIA - CIGU 2014. Disponível em < https://repositorio.ufsc.br/bitstream/handle/123456789/132016/2014325.pdf? sequence=1> Acesso em: 20 nov. 2016.

SAITO, C. A Pesquisa em educação ambiental em diferentes áreas do conhecimento algumas reflexões. Revista usp vol. 7, n. 2 - pp. 41-64, 2012. Disponível em: < http://www.revistas.usp.br/pea/article/viewFile/55961/59343> Acesso em: 13 nov. 2016.

SANTOS, BOAVENTURA de S.. A universidade no século XXI: Para uma reforma democrática e emancipatória da universidade/ Boaventura de Souza Santos- 3.ed- São Paulo: Cortez, 2011. Disponível em:

<http://www.ces.uc.pt/bss/documentos/auniversidadedosecXXI.pdf> Acesso em: 3 nov. 2016.

VILAS BOAS, ALEXANDRE D. S. A Enfermaria Militar De Jaguarão: Conhecendo SUA História. XI encontro estadual de história; história; memória; patrimônio. anpuhrs 2012. Disponível em: <http://www.eeh2012.anpuh-

rs.org.br/resources/anais/18/1346092720_ARQUIVO_ArtigoANPUH_2_.pdf >.Acesso em: 10 nov. 2016. 